\title{
A coupled vulnerability approach for European mountain regions
}

\author{
S. Fuchs
}

Institute of Mountain Risk Engineering, University of Natural Resources and Applied Life Sciences, Austria

\begin{abstract}
Defining natural hazard risk as a function of hazard and consequences, the ability to assess vulnerability is an essential step towards a reduction of these consequences. The concept of vulnerability is pillared by multiple disciplinary theories underpinning either a natural scientific or a socioscientific origin of the concept and resulting in a range of paradigms for vulnerability quantification. However, efforts to reduce susceptibility to hazards and to create disaster-resilient communities require intersections among these theories, since human activity cannot be seen independently from the environmental setting. Acknowledging different roots of disciplinary paradigms, issues determining structural, economic, institutional and social vulnerability are discussed with respect to mountain hazards in Europe. It is argued that structural vulnerability as the originator results in considerable economic vulnerability, generated by the institutional settings of dealing with natural hazards and shaped by the overall societal framework. If vulnerability and its counterpart, resilience, is analysed and evaluated by using such a comprehensive approach, a better understanding of the parameters that influence vulnerability will be achieved, taking into account the interdependencies and interactions between the disciplinary foci. The overall aim of this paper is to combine different approaches and to apply a coupled model by using a vulnerability-of-place criterion. Key issues of vulnerability are reconsidered, aiming at a general illustration of the situation in a densely-populated mountain region of Europe.
\end{abstract}

Keywords: risk analysis, susceptibility, vulnerability, mountain hazards. 


\section{Introduction}

Following the axiom that natural hazard risk is a function of hazard and consequences, the ability to determine vulnerability is an essential step for reducing these consequences and therefore natural hazard risk. Studies related to vulnerability of human and natural systems to mountain hazards, and of the ability of these systems to adapt to changes in the functional chain of hazards, are a relatively recent field of research that brings together experts from a wide range of disciplines, including natural scientists, social scientists, experts for disaster management and policy development, as well as economists, to name only a few. Stakeholders from these fields bring their own conceptual models to study vulnerability and adaptation, models which often address similar problems and processes using different languages [1]. While some research communities place emphasis on mitigation and emergency management $[2,3]$, others focus on large-scale global environmental processes, in particular with respect to climate change and its global to local impacts $[4,5]$. Since studies on vulnerability are rooted in a multiplicity of disciplines, there is neither a common definition nor a common theory developed of how to assess vulnerability. However, most conceptualisations have in common that the vulnerability of a studied system cannot be observed or measured directly, but rather it has to be deduced from distinct environmental settings. Despite differences between research communities, they acknowledge that the composition of vulnerability is driven by exposure, sensitivity (resistance), and response (resilience), and if comprehensively assessed it requires measurements of both environmental and social systems. However, studies on vulnerability of communities subject to mountain hazards are limited so far due to the inherent complexity in modelling vulnerability [6]. Several factors contributing to such complexity can be identified: (1) the lack of accurate data for reliable hazard analyses; (2) the strongly site-specific nature of process phenomena; (3) the difficulty in quantifying spatial impacts of those processes; (4) the quantitative heterogeneity of vulnerability of different elements at risk for qualitatively similar hazard mechanisms; and (5) the temporal variability in vulnerability.

As a consequence, social scientists and natural scientists often address different issues when they use the term vulnerability. Whereas social scientists tend to view vulnerability as representing the set of socio-economic factors that determine people's ability to cope with stress or perturbation [7], natural scientists often view vulnerability in terms of the likelihood of occurrence of specific process scenarios, and associated impacts on the built environment [8]. Thus, the consequences of natural hazards are generally measured in terms of damage or losses, either on an ordinal scale based on social values or perceptions and evaluations, or on a metric scale (e.g. in monetary units).

The diversity of concepts in vulnerability research leads to the question of whether or not people in European mountain regions are vulnerable to natural hazards, and how vulnerability could be addressed in the intersection between engineering approaches (technical or structural vulnerability), institutional vulnerability, economic vulnerability, and social vulnerability [6]. The overall 
aim in this paper is to apply different approaches emerging from social sciences and natural sciences to the situation in European mountain regions, and to discuss the arguments on a coupled vulnerability model following a vulnerability-of-place approach [9]. By bridging the gap between different disciplinary foci, key issues of vulnerability to mountain hazards and underlying paradigms will be reconsidered taking torrent events and associated processes as an example. By putting the geographical focus on Austria, and focusing on a densely-populated European mountain region, different dimensions of vulnerability and associated interactions will be highlighted.

\section{Structural vulnerability}

The approach of structural vulnerability is focussing on impact intensity and structural susceptibility of elements at risk, ranging from 0 (no damage) to 1 (complete destruction). From this technical point of view, as a general rule vulnerability assessment is based on the evaluation of parameters and factors such as building types, construction materials and techniques, state of maintenance, and presence of protection structures [8]. For this reason, vulnerability values describe the susceptibility of elements at risk facing different process types with different spatial and temporal distributions of process intensities (e.g., flow depths, accumulation heights, flow velocities and pressures, [10-12]).

If vulnerability is considered as a functional relationship between process magnitude or intensity, the resulting impact on structural elements at risk, and exposed values, vulnerability is related to the susceptibility of physical structures and is defined as the expected degree of loss resulting from the impact of a certain (design) event on the elements at risk. With respect to the hazardous processes, empirical parameters such as magnitude and frequency have to be evaluated based on probability theory. Thereby the magnitude-frequency concept plays a key role. When the activity of different hazard processes is compared on a given timescale some processes appear to operate continuously while others operate only when specific conditions occur.

By applying the concept of structural vulnerability, from an engineering point of view, considerable areas in European mountain regions are vulnerable to hazard processes. Even though the theory of vulnerability has been subject to extensive research and numerous practical applications over the past decades, considerable gaps still exist with respect to standardised functional relationships between impacting forces due to occurring hazard processes and the structural damage caused. For a major part these gaps result from the overall lack of data, in particular concerning: (1) losses caused by mountain hazards as a result of outstanding empirical classifications of damages; and (2) measurements of impact forces that caused these losses. Consequently, possible losses due to future events can only be predicted so far on the basis of relatively sporadic empirical classifications [6, 11, 13] (figure 1). The applied methods follow spatially explicit approaches, and are based on accumulation heights as a proxy 


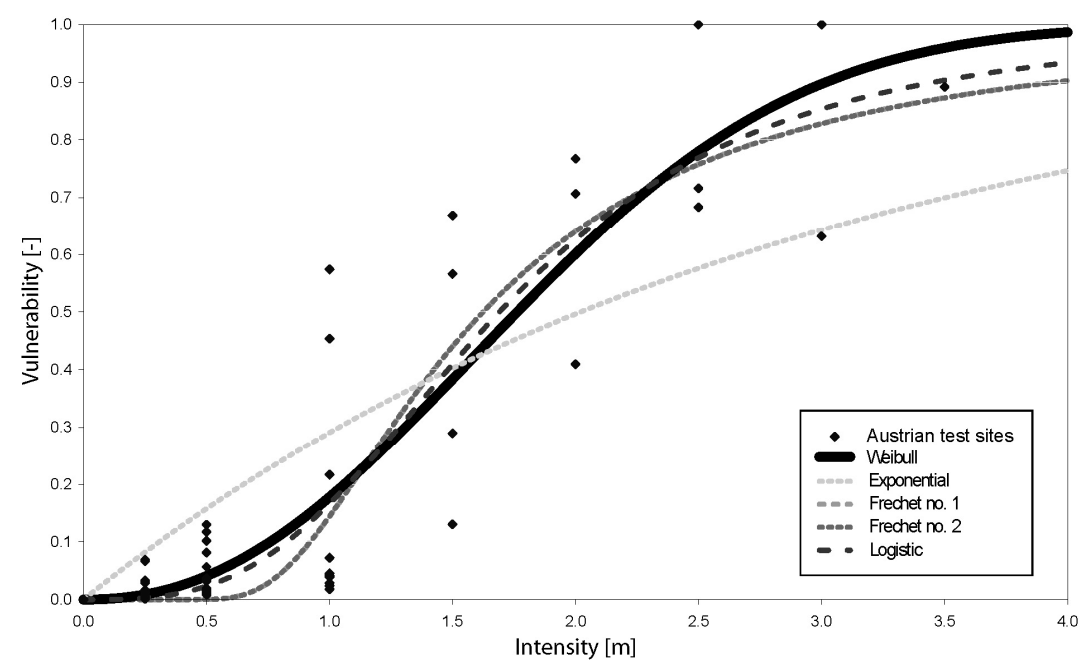

Figure 1: Vulnerability functions for residential buildings based on deposition height as a proxy for process intensities. Data from the test sites is indicated by dots; the best fitting function to describe the range in the analysed data is highlighted in bold (highest value of utility, adopted from [13]).

for process intensities, spatial data from elements at risk and average reconstruction values in dependence of the surface area on an object basis.

Even if such empirical relationships become increasingly important in determining vulnerability of structural elements at risk, the results only mirror the average expected systems behaviour (expected destruction due to impacting forces) for a specific setting, e.g., the entire area of a torrent fan presumably affected by a defined 1 in 150 year event. Since resistance against impact forces is dependent on the construction type of buildings, which typically has to be identified by local-scale field studies, determining structural vulnerability is very time-consuming and thus costly. Furthermore, as the effects of processes in the run-out area is not yet completely known [14, 15], modelled impact pressures can only be a rough estimate of the real system behaviour. To conclude, the component of structural vulnerability within risk analysis for mountain hazards is still roughly specified, mainly due to a lack of intensive experimental or observational data. Nevertheless, structural vulnerability is here understood to be the source for any other type of vulnerability, since if there was no impact due to a hazardous event on elements at risk, no loss would result, and the society as a whole would not suffer harm.

\section{Institutional vulnerability}

If the concept of vulnerability is defined by an anthropocentric concept, human behaviour is connected to the effects of natural hazards. Accordingly, individuals 
have a set of choices to reduce exposure and decrease vulnerability, which is determined by a framework consisting of the prevalent political system and related institutional structures. Hence, the perspective of institutional vulnerability is framed by the socio-political and cultural settings that together determine differential exposure to hazards and associated impacts, and differential capacities to recuperate from past impacts and to adapt to future threats. The concept of institutional vulnerability emphasises the humanenvironment interaction, and is defined as a state or condition of being moderated by existing inequities in resource distribution and access, as well as prevalent historical patterns of social domination and marginalisation [16]. With respect to the assumed aim of individuals to reduce vulnerability, and taking into account the relative complexity of understanding vulnerability to natural hazards, this set of choices is for a large part assigned to the political decision maker. As a result, in European mountain regions, individual precaution is increasingly neglected, and institutions take over the responsibilities of decisions and actions to mitigate natural hazard risk and decrease vulnerability. Such decisions and actions include efforts to: (1) reduce the probability of occurrence of potentially damaging processes, which is mainly attributed to the strategy of permanent mitigation and has in the past decades been institutionally taken over by administrative stakeholders [17]; and (2) reduce the adverse effects of natural hazard processes by shifting the probability of loss to a larger community, e.g. by taking out an insurance policy. Institutions can be classified into three types due to different prevalent aspects:

(1) Institutions defined as procedures and systems by means of which decisions are made within a society. Major systems include the market (from an economic point of view), the political system of democracy, other negotiating systems such as streamlined hierarchies, and the associated procedures of action.

(2) Institutions defined as formal and informal rules that determine human action, such as the legal system (determined by the respective political entity), the traditional framework (established due to religion), and social norms (developed though history).

(3) Institutions defined as organisations, such as the overall state structure, organisations and bureaucracies, and also clubs, the family, and informal groups of individuals that share a common aim.

Institutions shape the rules within a society and among different societal stakeholders, and with respect to vulnerability these institutions are of considerable importance to reduce the effects of natural hazards for individuals and the society.

Taking the Republic of Austria as an example, the institutional setting in dealing with risk is pillared by the overall principle of governmental responsibility for mitigating natural hazards [17]. However, issues related to an institutional reduction of vulnerability are not explicitly taken into account so far: Firstly, the legislation related to natural hazards is diverse due to the federal 
structure of the country. Several articles at federal level are supplemented by various regulations on the level of the federal states (Länder level) and even at community level, in particular with respect to land use planning. Secondly, risk awareness is not very prevalent throughout the country due to an information deficit related to: (1) the general occurrence of mountain hazards; and (2) mitigation strategies and concepts to avoid losses. Thirdly, different strategies to mitigate, and thus compensate, the effects of mountain hazards exist in Austria. These strategies, above all the governmental disaster fund and private insurance solutions, are neither particularly coordinated with respect to risk minimisation, nor do they create considerable incentives for individuals to prevent losses. This will be discussed in the following paragraphs in more detail.

It has been argued by several authors that besides political bodies and subordinated public authorities (often due to the respective legal framework) an insurance system could be a promising institutional setting in order to reduce vulnerability resulting from natural hazards (for a compilation see [18]). However, it has been claimed by other studies that the institutional framework of insurances against natural hazards is only a sub-optimal solution, in particular since the market for insurance works imperfectly or fails completely. The overall reason for these shortcomings can be ascribed to the phenomena of adverse selection and moral hazard, both of which can be observed in Austria due to a non-mandatory insurance system against natural hazards [17].

This market failure led to alternative institutional settings in Austria, namely different forms of governmental intervention in order to guarantee for a certain disaster assistance, compensation or governmental aid. Hence, in countries without mandatory insurance coverage risk-transfer lies within the responsibility of political institutions. (Another option could theoretically be not to decide for any formalised risk transfer, and consequently compensation that is not formally organised through an insurance company or a government could take place. In fact such informal risk transfer systems, e.g. between relatives, are quite common in less developed countries.) Internationally, government compensation is a proven solution to recouping hazard losses [19]. However, effectiveness is varied, schemes are often inefficiently administered and decisions politically motivated [20]. Apart from this overall criticism, any adoption of government compensation alongside an existing commercial hazard insurance industry is reported to act as a major disincentive towards individuals purchasing their own insurance [21]. The tendency of individuals not to insure (or take any other mitigation action) as a result of the reliance on expected financial assistance from government relief programs or donations by other individuals has been reported as charity hazard [22]. Governmental aid may lead to the phenomenon that people underinsure or do not insure at all due to anticipated governmental assistance and private charity after a hazard event that caused considerable losses. In addition to an insufficient amount of insurance coverage, financial compensation by the government might result in an inefficient allocation of public funds, as argued in [23] with respect to the federal disaster payments in the United States which were found to be considerably politically motivated. 
Apart from the effects of adverse selection and moral hazard, the market penetration of (in fact considerably limited) insurance policies is relatively low in Austria due to the mechanism of loss compensation by the disaster fund. The disaster fund, regularised by the Federal Act related to the Disaster Fund of 1966 [24] provided the legal basis for the provision of national resources for: (1) preventive actions to construct and maintain torrent and avalanche control measures; and (2) financial support for the Länder to enable them to compensate individuals and private enterprises for losses due to natural hazards in Austria. To finance the disaster fund, tied surcharges were put on income taxes, wage taxes, taxes on capital yields, and corporate taxes. After being subject to several amendments, the legal act from 1966 was revised by the so-called Federal Act related to the Disaster Fund of 1996 [25]. The budget of the disaster fund originates from a defined percentage (since 1996: 1.1\%) of the federal share on the income taxes, taxes on capital yield, and corporate taxes.

To benefit from these compensations, people are not required to pay written premiums nor do they have to otherwise contribute to the available funds - a strong incentive for more risky behaviour. Thus, the issue of third-party intervention, i.e., governmental funding, turned out to be a crucial aspect for a reduction of vulnerability in Austria. Furthermore, and this is presumably the second reason for low market penetration, the compensations paid out by the disaster fund are regularly shortened by (private) insurance compensations [17]. Consequently, risk-aware people underwriting private natural hazard insurances are de facto worse off than less aware people not taking precaution actions. This leads to decreasing demand in natural hazard insurance policies in Austria. Hence, people are vulnerable not due to political instability, but due to the system of loss compensation institutionally established as vulnerability occurs if institutions fail.

\section{Economic vulnerability}

Institutional vulnerability, as outlined above, in combination with structural vulnerability due to the impact of natural events on the built environment, and also on infrastructure facilities, leads to an economic vulnerability of values at risk exposed. Thus, resilience of individual or institutional proprietors is reduced. Thereby, a particular level or severity of a natural event becomes a hazard only in relation to existing human settings, i.e. the establishment of settlements and infrastructure in an area prone to mass movement processes such as torrent events - an a priori statement that is neither re-emerging nor unsurprising. Since hazards are so named because they cause economic damage and social disruption, the level and type of economic activity existing in an area - apart from the institutional framework of the society in that area, including previous decisions about specific adjustments to the natural event in question - is involved in assessing the vulnerable character of an event. However, attributing losses to a natural event alone might be misleading to quantify economic vulnerability unless these losses are relatively related to the economic activity in the studied region. 
A study on selected well-documented individual events and associated losses was carried out in order to differentiate the above-described overall values given [6]. A major budgetary item, also from the public perception point of view, is the regular support of the Länder by the disaster fund in providing subsidies for disaster compensation to individuals and legal entities affected by natural hazards. With these compensations, affected parties receive an indemnity up to a certain percentage of the overall amount of losses suffered. As in detail described in [6], an average share between $20 \%$ and $60 \%$ is paid out as governmental support to the aggrieved parties, with a considerable individual range between $0 \%$ and $100 \%$. Hence, losses tend to be event-specific, and thus individual losses might considerably exceed the average values reported for the whole country. However, the governmental support raises some issues related to the economic vulnerability of individuals towards mountain hazards.

Firstly, losses resulting from such hazards are a function of the individual impact of the event on elements at risk and the localisation of these elements at risk in relation to the spatial occurrence of this event. Consequently, losses are spatially variable and therefore - due to the probability of occurrence of multiple events in the same location - also temporally variable, which makes an exact estimation of loss incurrence difficult. Thus, the individual might underestimate its own vulnerability resulting from mountain hazards, in particular with respect to low-probability high-loss events.

Secondly, losses resulting from such events range between some negligible hundreds of Euros to several hundreds of thousands Euros in the case of complete destruction of buildings. Considering an average annual household income of around $€ 27,000$ in Austria (according to the 2006 EU-SILC, Austrian households have a median household income of $€ 27,317$ a year, while $10 \%$ of households have less than $€ 11,230$, and $10 \%$ have more than $€ 56,266$ p.a. at their disposal [6]), such losses might result in an individual insolvency in dependence on the personal earning capacities of affected people. The latter is of particular importance since for private households natural hazards are not entirely subject to any comprehensive insurance system in Austria so far [6]. Apart from very limited coverage included in some household policies up to a sum of between $€ 3,700$ and $€ 15,000$ per contract [21], losses resulting from mountain hazards are not insurable since the risk is not taken over by the insurance companies. Hence, the compensation mechanism of the disaster fund has to be considered as the only available instrument of institutionalised disaster aid in Austria (cf. Section 3). This may in turn fundamentally increase the economic vulnerability of persons affected.

Thirdly, due to the Federal Act related to the Disaster Fund of 1996 [25] only a certain part of the losses incurred might be eligible for compensation. Hence, a considerable share of the individual damage remains, and the related individual economic susceptibility might still be considerably high. This financial gap will only (at least partly) be closed if sufficient private disaster aid or donations by business entities is provided - turning the effects of a natural hazard into a typical charity hazard [6]. (A considerable amount of private and corporate donations is repeatedly collected by Austrian charity organisations, whereas the 
overall volume is hardly quantifiable. With respect to the 2002 inundations in Austria, the raised funds of registered relief organisations amounted to approximately $€ 73$ million cash and around $€ 10$ million in-kind donations, whereas more detailed data is not accessible. By means of these donations, a sum of $€ 7,000$ was paid out on average per claimant to support reconstruction [6].)

To conclude, societal and political decisions about reducing vulnerability do not necessarily meet the individual requirements of economic resilience. If losses due to natural hazards occur, the individual citizen is left with a considerable share of the damage due to missing guaranteed payments or liabilities evidenced by insurance policies - even if this might not mirror the economic preferences of individuals if they were asked. One major characteristic of any financial measure to reduce vulnerability towards mountain hazards in Austria is that the private sector does not supply them in a sufficient quantity given the potential economic benefits to society. Therefore, such measures have the characteristics of public goods or common (pool) resources [26]. Hence, the provision of protection against natural hazards to reduce economic vulnerability is commonly regarded as a governmental duty. However, in Austria, direct governmental interventions do not offer any explicit incentive for individuals to react in a way which is vulnerability-minimising and to subsequently provide prevention measures on an individual basis. Consequently, a considerable social vulnerability may result.

\section{Social vulnerability}

Social vulnerability can be defined as "the characteristics of a person or group and their situation that influence their capacity to anticipate, cope with, resist and recover from the impact of a natural hazard" [27, p. 11]. Hence, vulnerability is the inherent characteristics or qualities of social systems that create the potential for harm [9]. Defined in this way, vulnerability involves a combination of factors determining the degree of which an individual or the society is put at risk by a discrete event in nature. Consequently, some groups are more prone to damage, loss and suffering in the context of mountain hazards. Key variables explaining variations of impact include class, occupation, ethnicity, gender, disability and health status, age, and the nature and extent of social networks. Hence, vulnerable groups are those that face considerable difficulties in reconstructing their livelihoods following disasters. Livelihood thereby is understood in its broadest sense by the response an individual or social group has by a bundle of resources that can be used to recover from the adverse impact of a hazard event. Such resources include information, cultural knowledge, social networks, legal rights, as well as physical resources [27] - and monetary reserves or any institutional settings.

The concepts of social vulnerability show evidence for a changing characterisation. As stated in [9], there are no distinctive and broadly agreed definitions of vulnerability in social sciences. In contrast, multiple definitions not only differ between several degrees of voluntariness when coping with natural hazards, but also consider individual as well as social influences, filtered by certain conditions that determine an individual's perception of risk. 
Consequently, with respect to the perception and assessment of vulnerability, the evaluation of vulnerability through individuals can be described as a result of cultural environment, perception of susceptibility and associated communication [6]. Thereby, the cultural environment provides the overall setting in terms of an origin of several social factors and historically rooted cultural ideals being both individually and socially determined. Social factors amplify the perception of vulnerability, apart from familiarity and the behaviour of actors from authorities responsible for dealing with natural hazard risk due to the production of social norms through communication. Social factors determining the evaluation of vulnerability interact with individual factors, such as the degree of voluntariness when exposed to hazardous events, the personal experience resulting from previous events, concernment, attitude, adaptation strategies and processing of information [6]. The perception of the degree of vulnerability by the individual results from a perception filter set between the cultural environment and the natural hazard, depending on the severity of the event. Communication, on the other hand, is again the result of a filtering of perception, and takes place between individuals or groups and between institutions and individuals. Communication shapes the evaluation of vulnerability. Thereby, target-oriented delivering of information on hazard and risk is of virtual importance to enable the evaluation of vulnerability and thus to create disaster-resilient communities [28]. Finally, the evaluation of vulnerability leads to adjustments and coping strategies either to control the hazard or to reduce susceptibility.

Vulnerability is rooted in the actions and multiple attributes of human actors, manifested simultaneously on more than one (temporal and spatial) scale, and influenced and driven by multiple stresses and communication. Consequently, the concept of social vulnerability is embedded into the overall concept of vulnerability, however defined. Hence, it refers to more than social characteristics of entities exposed to stressors since it also encompasses features of potential physical damage in the built environment. Multiple frameworks, conceptual models, and vulnerability assessment techniques have been developed to advance both the theoretical underpinnings and practical applications of the social vulnerability concept [9, 29].

Human-environment interaction is of particular interest when questioning vulnerability resulting from mountain hazards. The concept originating from the social-ecological systems theory "reflects the idea that human action and social structures are integral to nature and hence any distinction between social and natural systems is arbitrary" [29, p. 268]. Vulnerability is positioned as the degree to which a system is susceptible to adverse effects and the associated stress to which this system is unable to cope with. Therefore, the sensitivity and adaptive capacity of the system are key parameters, both of which could be defined as resilience of the system - the magnitude of disturbance that can be absorbed before a (social) system changes to a radically different state [30], or the susceptibility of the system to disturbances and the associated speed of return to the equilibrium steady state or stability [31]. By defining vulnerability as the counterpart of resilience, and consequently viewing both terms as separate but linked concepts, the two aspects of systems' stability have considerably different 
consequences for evaluating, understanding and managing mountain hazards. Both aspects of vulnerability focus on the dynamics of social structure when explaining vulnerability - either in terms of system flips, or in terms of systems' stability.

The first aspect of resilience, focusing on the amount of disturbance that can be sustained before a change in system control and structure occurs, refers to the ability of a society to cope with the impact of hazardous events unless the effects are so severe that a sudden change in livelihood conditions occurs, which results in political instability or even chaos. The second aspect concentrates on stability and is probably therefore more applicable within the framework of managing mountain hazards in Europe. Following the latter, even in case of extreme events, the vulnerability of the (social) system to stress is considerably low due to social networks, economic settings as well as institutional and political factors, and consequently the speed of return to the equilibrium steady state, defined as the prevailing livelihood conditions, is fast. In other words, even if the magnitude of a hazardous event is high, the vulnerability is considerably low due to multiple compensation mechanisms installed in European societies, ranging from spreading risk to a larger community to governmental compensation and private donation. Therefore, ex-post recovery following an event is wellorganised, and the initial systems state is re-established immediately or with only little delay. Strong evidence is therefore provided by the relatively immediate return to normality in public life after major hazard events [6].

Following these arguments, it is not social inequity, lack of access to education, or a question of gender that set the framework for social vulnerability to mountain hazards in Austria (it has to be noted, however, that such issues are often argued with respect to Central European countries [6]). In contrast, it is the institutional framework composed from land use regulations, risk transfer mechanisms, individual desires and anticipated economic benefits. Consequently, this framework can be used to reduce social vulnerability to natural hazards.

\section{Implications for risk management}

To manage natural hazard risk, a broader understanding of the concept of vulnerability is needed in order to reduce losses resulting from hazardous events. Multiple conceptualisations of vulnerability exist that show inherent differences in underlying theories due to sectoral disciplinary foci. Acknowledging these different roots of the multiple concepts of vulnerability, it becomes apparent that only by a multi-dimensional approach the overall aim of reducing natural hazards risk can be achieved. It had been shown in the previous sections that disciplinary approaches in vulnerability assessment are linked with each other, leading to the conclusion that structural, economic, institutional and social vulnerability are interdependent and interacting.

Human actions in mountain environments affect the state of vulnerability, and, in turn, the state of vulnerability shapes the possibilities of human action. More crucially, there are the differences of approach between those that see 
vulnerability in terms of variations in exposure to hazards and those that concentrate on variation in people's capacity to cope with hazards. Studies in the former tend to focus on the distribution of some hazardous condition, the human occupancy of this hazardous zone and the degree of loss associated with the occurrence of a particular event. Studies in the latter tend to highlight the social construction of vulnerability or the socio-political process by which people are made vulnerable. Such different disciplinary concepts of vulnerability, and associated paradigms of vulnerability, have at least some common elements that could be used in order to better evaluate vulnerability (and its counterpart, resilience) to mountain hazards in European mountain regions. The challenge in moving from individual disciplinary views to an interdisciplinary analysis of vulnerability by understanding the linkages and interactions of pure technical and pure socioscientific approaches should be undertaken. There is no doubt that elements at risk are highly susceptible if they are located in the run-out areas of mountain hazards.

Vulnerability of a specific location is triggered by structural vulnerability of elements at risk affected, which has to be evaluated in-depth in order to provide robust values for quantifying the respective resulting risk [10,11]. Structural vulnerability is complemented by economic resilience, the institutional framework, and societal settings (figure 2). Depending on the severity of the event and on additional aspects related to the temporal political situation, compensation is paid out that might considerably reduce the individual financial vulnerability of people concerned. However, unless loss compensation is solely based on public donation, considerable shares of the damage suffered remain with the claimants, institutional vulnerability results and economic vulnerability remains - therefore, society in European mountain regions might still be vulnerable to mountain hazards. A reduction of institutional vulnerability is essential to result in a considerable reduction of societal vulnerability. One major step towards a more disaster-resilient society is information [28], highlighting the interaction between prevention and precaution, as well as creating incentives for loss-reducing actions on the local level to reduce the structural vulnerability to natural hazards in mountain regions.

To conclude, different concepts of vulnerability presented in the previous sections have different roots, different scientific methods, and therefore different informative values. Integrating in a holistic way the contributions of social sciences, natural sciences, politics, and economy would not necessarily (at the present stage) result in one individual integral method generally applicable, but in a concept offering complementary results that might be combined for a deeper understanding of hazard and risk (figure 2).

Following the definition of vulnerability in natural sciences, a functional relation between the hazardous event (threat) and the values at risk exposed is the prerequisite for risk. Exposure defines the susceptibility of the values at risk to be affected by the hazard due to their location in the area of influence of the process and a lack of physical resistance (structural vulnerability). Resistance, defined as the ability to withstand a hazard, could be increased by constructive measures such as local structural protection $[12,17]$. On the other hand, the 


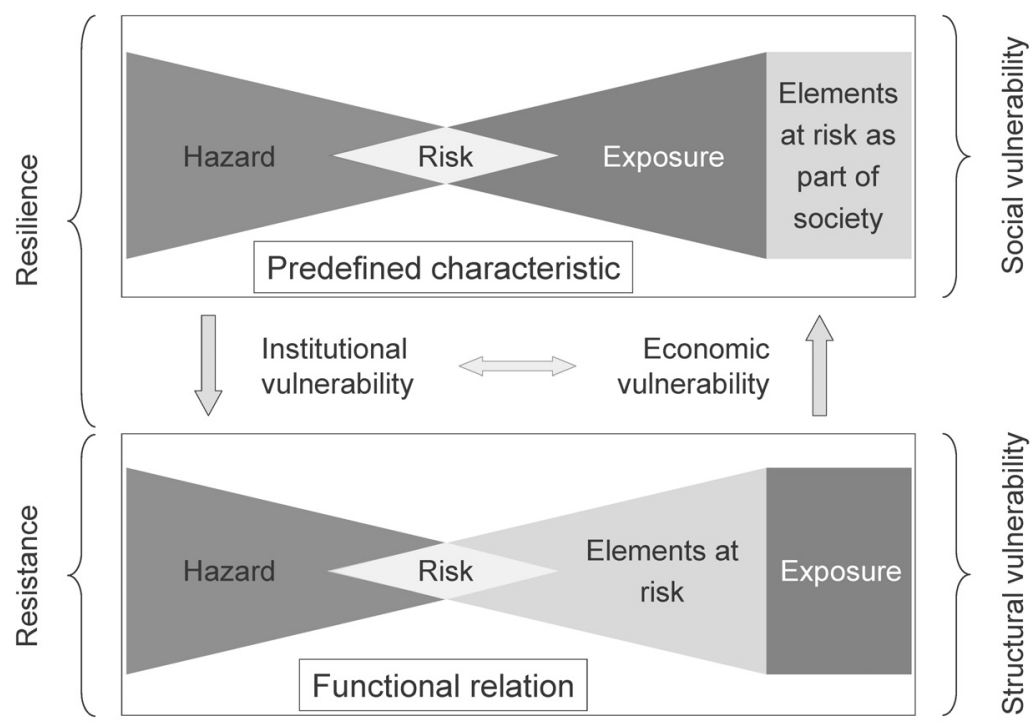

Figure 2: Relationship between threat, values at risk, exposure, and risk defined for structural and social vulnerability in relation to economic and institutional vulnerability for European mountain regions (adopted from [6, p. 349]).

concept of risk in social sciences is pillared by the intersection of the hazardous area and the general exposure of society as a whole; values at risk are understood as part of the society. Hence, social vulnerability is the underlying predisposition to suffer harm due to disadvantageous conditions, predefined characteristics and relative weaknesses related to social factors. These two poles of vulnerability are linked by: (1) economic vulnerability directed from structural vulnerability to social vulnerability, since individuals or societies cannot be vulnerable if they are not threatened; and (2) institutional vulnerability directed antipodal. While the first is related to the concept of endowment, the latter is related to entitlement. Social units in general have different coping capacities, which enable them to respond to a threat. Endowment is linked to these capacities since it defines possibilities to reduce economic susceptibility and to increase the respective resilience by e.g. loss transfer mechanisms. Entitlement, on the other hand, provides the framework of legal rights to access necessities of life, such as e.g. safe places for land development, which in turn is determined by the social unit's endowments [4]. Structural vulnerability results in loss, which in turn causes economic vulnerability to individuals or the society. Conversely, institutional settings of the society condition the height of structural vulnerability if coping strategies are developed and implemented. These coping strategies, e.g., the adoption of mandatory insurance solutions, will result in an increased resilience which is defined as the ability to recover from the adverse impacts of a threat [17]. Both concepts, the concept of vulnerability from a socioscientific 
perspective and from a natural scientific perspective, convolute and supplement each other in a quasi-circular flow, whereas distinct dependencies between economic vulnerability and the institutional settings exist.

\section{References}

[1] Brooks, N., Vulnerability, risk and adaptation, Tyndall Centre for Climate Change Research Working Paper, 38, pp. 1-16, 2003.

[2] Pelling, M., Natural disasters and development in a globalizing world, London, 2003.

[3] Bankoff, G., Frerks, G., \& Hilhorst, D, Mapping vulnerability. London, 2004.

[4] Turner II, B., Kasperson, R., Matson, P., McCarthy, J., Corell, R., Christensen, L., Eckley, N., Kasperson, J., Luers, A., Martello, M., Polsky, C., Pulsipher, A., \& Schiller, A., A framework for vulnerability analysis in sustainability science, Proceedings of the National Academy of Sciences of the United States of America, 100, pp. 8074-8079, 2003.

[5] Renn, O., Concepts of risk: An interdisciplinary review - part 2: Integrative approaches, Gaia, 17, pp. 196-204, 2008.

[6] Fuchs, S., Susceptibility versus resilience to mountain hazards in Austria paradigms of vulnerability revisited, Natural Hazards and Earth System Sciences, 9, pp. 337-352, 2009.

[7] Allen, K., Vulnerability reduction and the community-based approach, ed. Pelling, M., Natural disasters and development in a globalising world, London, pp. 170-184, 2003.

[8] Fell, R., Corominas, J., Bonnard, C., Cascini, L., Leroi, E. \& Savage, W., Guidelines for landslide susceptibility, hazard and risk zoning for landuse planning, Engineering Geology, 102, pp. 85-98, 2008.

[9] Cutter, S., Barnes, L., Berry, M., Burton, C., Evans, E., Tate, E. \& Webb, J., A place-based model for understanding community resilience to natural disasters, Global Environmental Change, 18, pp. 598-606, 2008.

[10] Fuchs, S., Heiss, K. \& Hübl, J., Towards an empirical vulnerability function for use in debris flow risk assessment, Natural Hazards and Earth System Sciences, 7, pp. 495-506, 2007.

[11] Fuchs, S., Vulnerability to torrent processes, ed. Brebbia, C. \& Beriatos, E., Risk Analysis VI, Southampton, pp. 289-298, 2008.

[12] Holub, M. \& Fuchs, S., Benefits of local structural protection to mitigate torrent-related hazards, ed. Brebbia, C. \& Beriatos, E., Risk Analysis VI, Southampton, pp. 401-411, 2008.

[13] Totschnig, R., Sedlacek, W. \& Fuchs, S., A quantitative vulnerability function for fluvial sediment transport, Natural Hazards, in press.

[14] Fuchs, S., Bründl, M. \& Stötter, J., Development of avalanche risk between 1950 and 2000 in the municipality of Davos, Switzerland, Natural Hazards and Earth System Sciences, 4, pp. 263-275, 2004.

[15] Fuchs, S., Keiler, M., Zischg, A. \& Bründl, M., The long-term development of avalanche risk in settlements considering the temporal variability of 
damage potential, Natural Hazards and Earth System Sciences, 5, pp. 893901, 2005.

[16] Eakin, H. \& Luers, A., Assessing the vulnerability of social-environmental systems, Annual Review of Environment and Resources, 31, pp. 365-394, 2006.

[17] Holub, M. \& Fuchs, S., Mitigating mountain hazards in Austria legislation, risk transfer, and awareness building, Natural Hazards and Earth System Sciences, 9, pp. 523-537, 2009.

[18] Ungern-Sternberg, T. v., Efficient monopolies - The limits of competition in the European property insurance market, Oxford, 2004.

[19] Arnell, N., Flood insurance, ed. Parker, D., Floods, London, pp. 412-424, 2000.

[20] Priest, S., Clark, M. \& Treby, E., Flood insurance: the challenge of the uninsured, Area, 37, pp. 295-302, 2005.

[21] Gruber, M., Alternative solutions for public and private catastrophe funding in Austria, Natural Hazards and Earth System Sciences, 8, pp. 603-616, 2008.

[22] Browne, M. \& Hoyt, R., The demand for flood insurance: empirical evidence, Journal of Risk and Uncertainty, 20, pp. 291-306, 2000.

[23] Garrett, T. \& Sobel, R., The political economy of FEMA disaster payments, Economic Inquiry, 41, pp. 496-509, 2003.

[24] Republik Österreich, Bundesgesetz vom 9. September 1966 über den Katastrophenfonds, $B G B l$., 207/1966, 1966.

[25] Republik Österreich, Katastrophenfondsgesetz 1996, $B G B l$., 201/1996, 1996.

[26] Fuchs, S. \& McAlpin, M., The net benefit of public expenditures on avalanche defence structures in the municipality of Davos, Switzerland, Natural Hazards and Earth System Sciences, 5, pp. 319-330, 2005.

[27] Wisner, B., Blaikie, P., Cannon, T. \& Davis, I., At risk, London, 2004.

[28] Fuchs, S., Spachinger, K., Dorner, W., Rochman, J. \& Serrhini, K., Evaluating cartographic design in flood risk mapping, Environmental Hazards, 8, pp. 52-70, 2009.

[29] Adger, N., Vulnerability, Global Environmental Change, 16, pp. 268-281, 2006.

[30] Holling, C., Resilience and stability of ecological systems, Annual Review of Ecology and Systematics, 4, pp. 1-23, 1973.

[31] Holling, C. \& Gunderson, L., Resilience and adaptive cycles, ed. Gunderson, L. \& Holling, C., Panarchy, Washington, pp. 25-63, 2002. 